\title{
Audiences Perceptions of Informative Programs at Jimma Fana FM 98.1 in Jimma, Ethiopia
}

Alemayehu Negash ${ }^{1}$, Getaw Girma ${ }^{2}$ and Netsanet Jemal ${ }^{3 *}$

${ }^{1}$ Assistant Professor of Applied Linguistics and Development (ALD), Coordinator of CBE and Partnership, CSSH, Jimma University, Jimma, Ethiopia ${ }^{2}$ Assistant Professor of Teaching English as a Foreign Language(TEFL), Instructor in Department of English Language and Literature, Jimma University, Jimma, Ethiopia ${ }^{3}$ Jouranist at Jimma Fana FM Radio Station, Jimma, Ethiopia

\begin{abstract}
The main objective of this study was to assess audiences' perceptions towards informative programs broadcasted from Jimma Fana FM 98.1 radio station in Jimma, Ethiopia. Cross-sectional research design was used in the study as a research design. Primary data were collected from 218 respondents using questionnaire and focus group discussions. The collected data were analyzed using quantitative and qualitative methods of data analysis. The finding of the study revealed that audiences had very good perceptions towards informative programs broadcasted from Jimma Fana FM 98.1. Finally, conclusions and recommendations were given on the basis of the above finding.
\end{abstract}

Keywords: Perceptions; Informative programs Jimma Fana FM 98.1 Radio station; Ethiopia

\section{Introduction}

Media play a powerful role in people's lives nowadays. They further play roles in formulation of images and beliefs of the people calls the social and political images created by media as "pictures in our heads." Media images enable people to have frequent and meaningful interactions with the society [1].

All types of media function as socialization agents and different media individually and collectively work to shape a person's perceptions and communication directly or indirectly [2]. However, among the different types of media, scholars spent time researching the impact that television has had on personal and societal perceptions. This is largely due to the rapid growth of the television industry and its pervasiveness in everyday life [2].

Meanwhile, Jimma Fana FM 98.1 radio station covers all districts found in Jimma zone, partial IlluAbabora, East Wellega, Yem special district from South Nations Nationalities People Regional State, partial Dawuro zone, Hadiya zone and Kafa zone. The Radio station transmits news, entertainment, informative and advertisement programs for the community by addressing social, economic and political issues. Its local program covers a total of 48 hours per week in Afan Oromo and Amharic languages. The station addresses approximately 5.5 to 6 million people. Form the foregoing discussion, one can understand that Fana FM 98.1 radio station has effects on its audiences. However, from experience it appears that there is a dearth of studies which have been conducted on impacts and influences of Fana FM 98.1 radio station on its audiences in Jimma town. It was based on this general background that this study was conducted.

\section{Statement of the problem}

People form perceptions according to what media present to them [3] though different factors such as past experience, cultural expectations, motivations, moods, needs and attitudes influence their perceptions [4]. A number of studies have been conducted in other countries related to media perceptions. For instance, Matthes [5] conducted a study on the affective underpinnings of hostile media perceptions, focusing on exploring the distinct effects of affective and cognitive involvement in Austria. Matthes's study proves that affective involvement can explain the hostile media effect over and beyond cognitive involvement. Amin
[6] on his part conducted a study on journalists' perceptions and attitudes towards Arab media in Egypt. The study showed that press freedom in Arab countries and the performance of Arab journalists are still threatened by a censorial political culture, one that develops in an environment usually dominated by a single political party. D'Angelo and Lombard [7] further conducted a study on the effects of press frames in political campaign news on media perceptions in the United States. The study revealed that media perceptions were differently activated by virtue of exposure to the press frames.

In the context of Ethiopia, however, it seems that there is a paucity of empirical studies which have been conducted to assess public perceptions and audiences' reactions on media. To mention a few studies, Milkesa [8] conducted a case study on the role of Zami 90.7 and Sheger 102.1 FM radios for social development in Addis Ababa. The study revealed that these private FM radios have programs that are entertaining, educative, socially responsive and commercially profitable. The research further indicated that although these FM radio stations give much emphasis on educative and socially relevant issues, there is a lack of studies which have been conducted on audiences' perceptions of other FM radio stations in the country. Biset [9] also conducted a study on media preferences and perceptions of instructors at Bahir Dar University, Ethiopia. The study reveals that Bahir Dar University instructors consume news on a daily basis. With regard to media usage, the study shows that television stations, radio stations, and websites were the most chosen information source of respondents. Among television programs, foreign television news programs were mostly viewed by respondents, and Ethiopian television has taken the lead compared to other national television programs.

Nevertheless, to the knowledge of the present researchers, there

*Corresponding author: Netsanet Jemal, Jimma Fana FM Radio Station, Ethiopia, Tel: +251-0917010380; E-mail: njemal98@yahoo.com

Received June 20, 2017; Accepted October 20, 2017; Published October 23 2017

Citation: Negash A, Girma G, Jemal N (2017) Audiences Perceptions of Informative Programs at Jimma Fana FM 98.1 in Jimma, Ethiopia. J Mass Communicat Journalism 7: 351. doi: 10.4172/2165-7912.1000351

Copyright: @ 2017 Negash A, et al. This is an open-access article distributed under the terms of the Creative Commons Attribution License, which permits unrestricted use, distribution, and reproduction in any medium, provided the original author and source are credited. 
is no study which has been conducted on the informative programs transmitted from Fana FM 98.1 radio station in Jimma town, albeit the organization itself conducted two shallow surveys using Amharic questionnaire. Here, it is worth mentioning that Jimma Fana FM 98.1 radio station transmits programs in Afan Oromo and Amharic languages to its audiences. However, no attempt has been made to study the perceptions of Afan Oromo and Amharic language speakers on the mass media in Jimma town. As a result, currently it is not known whether Jimma Fana FM 98.1 radio station is bringing about changes to the community of Jimma town or not. Therefore, this research tried to fill this research gap by studying the perceptions of audiences towards informative programs transmitted from Jimma Fana FM 98.1 radio station in Jimma town.

\section{Objectives of the Study}

\section{General objectives}

The main objective of this study is to assess the audiences' perception towards informative programs broadcasted from Jimma Fana FM 98.1 radio station.

\section{Specific research questions}

The study attempted to answer the following research questions in particular:

How do the audiences evaluate the effectiveness of the contents, styles, languages and time of Jimma Fana FM 98.1.radio station?

To what extent they examine whether the informative programs transmitted from the radio station are closely related with the livelihood of the majority of the audiences?

How do the audiences evaluate the effectiveness of informative programs broadcasted from Jimma Fana FM 98.1 radio station in general?

\section{Significance of the study}

The researchers believed that the study will provide important information about the perceptions of audiences to the management of the radio station so that they improve the performance of the five informative programs based on the audiences' preferences. This, in turn, may enable the audiences of Jimma Fana FM 98.1 radio station to be more beneficiaries of the five informative programs transmitted from the radio station. Furthermore, it was hoped that the study may provide important information for policy makers who strive to bringing social changes and development through mass media in Ethiopia. Moreover, it was believed that the study will provide insights for future researchers who want to study the issue in more detail from different perspectives.

\section{Scope of the study}

There are different programs which are broadcasted from Jimma Fana FM 98.1 radio station that is found in Jimma town, which is located in Southwest Ethiopia at a distance of 335 kilometers from Addis Ababa. But this study assessed audiences' perceptions towards only the five informative programs viz. Amharic and Afan Oromo news programs, Hello Fana program, Yebeteseb Maed program, Tibeb Fana program and Gaddisa Jimata program broadcasted from the radio station in 2016 academic year. As it is stated in the background section above, Jimma Fana FM 98.1 radio station covers a wide area, and it was difficult to study the perceptions of all audiences of the radio station. Therefore, the study is delimited to studying the perceptions of audiences only in Jimma town. With regard to the limitation of the study, the study was conducted only on the five informative programs broadcasted from Jimma Fana FM 98.1 radio station in Jimma town. Thus, the findings of the study may not be generalized to all other radio programs broadcasted from radio stations which are found in Ethiopia and in other countries.

\section{Review of Related Literature}

\section{Functions of media}

Media include newspapers, magazines, television, radio and the internet. Media can be classified as print media (such as newspapers, magazines, books and billboards) electronic media (like radio, television and computers) and photographic media (such as still photography, film and video) [10]. Business organizations use media for communicating information to the public because they know that media have huge impacts on audiences beliefs and perceptions. Media provide basic knowledge and information to the public regarding different national and international issues. Audiences make their informed judgments and perceptions based on the information provided by media to them. Media also play a role in socializing children. They also have the power of turning the world in to a 'globalized village' for audiences. Media (mainly the new media or the internet) are not only successful in telling us how to think, but they are successful in telling us what to think about. Media set the agenda for our decision making and influence our social and political perspectives [3].

Societies are affected by the function of media, but this could vary from individual to individual.

According to McCombs and Maxwell [3], media are 'social institutions'. A social institution is an organization that is critical to the socialization process; it provides a support system for individuals as they struggle to become members of a larger social network.

Maxwell [11] further describe, "New media have the power of setting a nation's agenda and focusing the public attention on a few key public issues." This shows that new media have the powers of guiding public opinion towards specific direction. New media change the perception of people in some specific way so that people start thinking or perceiving in a way media want to.

\section{Definition of perception}

The term perception has different meanings. A common element in most meanings is that perception involves the analysis of sensory information. When cognitive psychologists talk about perception, they usually refer to the basic cognitive processes that analyze information from the senses, and they define that sense perception is the use of our senses (sight, touch, hearing, smell and taste) to acquire information about the world around us and to become acquainted with objects, events and their features [12]. According to Feldman, "Perception is the sorting out, interpretation, analysis and integration of stimuli through our sense organs and brain." Perception is a process by which an individual selects, organizes and interprets information inputs to create a meaningful 'picture' of the world.

Different individuals can perceive a message in different ways. This is because perception is a product of three things: physical stimuli (e.g., programs), the relationship between the stimuli and the immediate environment and the psychology of the individual [12]. Media play a very significant role in making up audiences' perceptions towards certain issue [13]. Styhre [14] argues that the content presented by media can be consumed by audiences differently depending on the 
audiences' culture-induced belief, attitude and behavior towards the media and the media's content.

\section{Theoretical framework of the study}

'Agenda setting theory' which is a mass communication theory has been used as a theoretical framework for this study. This theory was developed in 1972 by Maxwell McCombs and Donald Shaw. Agenda setting theory states that media such as radio, newspapers and television establish an agenda for their audiences by highlighting some issues, events and people, and by downplaying others. In other words, by selecting what events and issues to cover and how to present them, media set the public agenda. Agenda setting involves two distinct processes. Firstly, media direct audiences to pay attention to particular topics by giving those topics coverage. Secondly, media lead audiences to ignore or give minimum attention to other topics by covering them barely or not at all. Agenda setting theory further describes that a medium has an ability to select events, people and phenomena and offers frames or ways of seeing these events, people and phenomena to its audiences $[15,16]$

\section{Research Methodology}

\section{Research design}

Cross-sectional research design enables researchers to collect data at one point of time, thereby enabling researchers to obtain results relatively quickly than other types of research designs. Cross-sectional research design is further more cost effective compared to other types of research designs. It is also ideal research design to describe characteristics of a population such as their attitudes, intentions and perceptions. Furthermore, it enables to avoid problems related to sample attrition. Moreover, cross-sectional research design enables to use qualitative and quantitative data [17]. Thus, cross-sectional research design was used in the study.

\section{Participants of the study}

Totally, 218 participants (200 participants for questionnaire and 18 participants for focus group discussions) were participated in the study. The participants of the study were selected from the four Kebeles which are Bosaadis, Bosakito, Hermata and Hermatamentina that are found in Jimma town. The participants were youths, females and elders who speak Amharic and Afan Oromo languages.

\section{Data gathering tools}

Primary data gathering tools which are questionnaire and focus group discussion were used to collect the necessary firsthand data for the study.

\section{Questionnaire}

Structured questionnaire was used to collect primary data for the study. The questionnaire contains open ended questions. Ordinal level of measurement which is a five point Likert-Scale that is widely used to measure perceptions and attitudes is used in the questionnaire. The questionnaire was commented by scholars who have knowledge in the research area, and necessary modifications have been made in the questionnaire based on the comments given by these scholars. It was further pre-tested in other Kebeles found in Jimma town using other respondents who did not participate in the final data collection. The identity of the researchers and the purpose of the study were also described to the respondents of the questionnaire so that the respondents fill in the questionnaire based on their willingness. The questions in the questionnaire were translated in to Amharic and Afan Oromo languages which are the mother tongue languages of the respondents so that the respondents give clear responses in the questionnaire as well.

\section{Focus group discussion}

Focus group discussion was used to collect necessary data for the study. Focus group discussion guides were designed based on the objectives of the study and review of related literature made in Chapter two, and they were used. Then, the guides were commented by scholars who had knowledge in the research topic. The necessary improvements were made in the focus group discussion guides based on the comments and suggestions given by the scholars before they were used. As to the moderation of focus group discussions, one of the researches moderated or facilitated the focus group discussions. With regard to the composition of discussants in the focus group discussions, the focus group discussions were made with youth, women/females and elders separately based on the principle of homogeneity in a focus group discussion. This is because gender, age and status (being major factors) affect the quality and level of interaction in focus group discussions [18]. Seven participants were participated in each focus group discussions as well. The focus group discussion was made with participants using their mother tongue languages which are Amharic and Afan Oromo languages so as to get clear data for the study.

\section{Sampling techniques}

Jimma town was selected purposefully to be the study area, for there is a dearth of study conducted on the perceptions of audiences towards informative programs transmitted from Jimma Fana FM 98.1 radio station in the town. The study populations were the residents of Jimma town who have been selected purposively from four Kebeles found in Jimma town. From 17 Kebeles found in the town, the four Kebeles (Bosaadis, Bosakito, Hermata and Hermatamentina) have been selected using simple random sampling technique which is lottery method.

\section{Methods of data analysis}

Descriptive statistics which are frequency distributions and percentage were used to analyze the quantitative data collected using questionnaire. Univariate descriptive analysis was used to analyze one item at a time. On the other hand, the qualitative data that were collected using focus group discussion were reported qualitatively.

\section{Ethical considerations}

A letter of cooperation was written from the research and postgraduate coordinating office of the College of Social Sciences and Humanities at Jimma University so as to get access to the research site. The identities of the researchers and the purpose of the study were explained to the participants of the study. The confidentiality of the research was assured to the participants as well. These research ethical issues were done so as to get the participants' informed consent. Furthermore, the collected data were analyzed and interpreted honestly without data rigging.

\section{Data analysis and interpretation}

This section deals with the analysis and interpretation of the data gathered through questionnaire and focus group discussion. Audiences' perceptions towards the five informative programs broadcasted from Jimma Fana FM 98.1 radio station are analyzed and interpreted below (Table 1). 


\begin{tabular}{|c|c|c|c|c|c|c|c|c|c|c|c|}
\hline \multirow[t]{2}{*}{ No } & \multirow[t]{2}{*}{ Statements } & \multicolumn{2}{|c|}{ Strongly Agree } & \multicolumn{2}{|c|}{ Agree } & \multicolumn{2}{|c|}{ Disagree } & \multicolumn{2}{|c|}{ Strongly Disagree } & \multicolumn{2}{|c|}{ Undecided } \\
\hline & & $\mathbf{F}$ & $\%$ & $\mathbf{F}$ & $\%$ & $\mathbf{F}$ & $\%$ & $\mathbf{F}$ & $\%$ & $\mathbf{F}$ & $\%$ \\
\hline 1 & $\begin{array}{l}\text { I listen Amharic and Afan Oromo news programs transmitted from } \\
\text { Jimma Fana FM } 98.1 \text { because the news gives me new information. }\end{array}$ & 97 & 53 & 68 & 34.4 & 11 & 6.01 & 4 & 2.1 & 4 & 2.1 \\
\hline 2 & $\begin{array}{l}\text { I listen Amharic and Afan Oromo news programs transmitted from } \\
\text { Jimma Fana FM } 98.1 \text { because the news provides me credible } \\
\text { information. }\end{array}$ & 106 & 57.9 & 45 & 24.5 & 21 & 11.4 & 11 & 6.01 & 4 & 2.1 \\
\hline 3 & $\begin{array}{l}\text { I listen Amharic and Afan Oromo news programs transmitted from } \\
\text { Jimma Fana FM } 98.1 \text { because the transmission times of the news } \\
\text { are suitable for me. }\end{array}$ & 93 & 50.8 & 56 & 30.6 & 19 & 10.3 & 8 & 4.3 & 7 & 3.8 \\
\hline 4 & $\begin{array}{l}\text { I listen Amharic and Afan Oromo news programs transmitted from } \\
\text { Jimma Fana FM } 98.1 \text { because the ways of the news broadcasting } \\
\text { are attractive for me. }\end{array}$ & 77 & 42.07 & 65 & 35.5 & 25 & 13.6 & 9 & 4.9 & 7 & 3.8 \\
\hline 5 & $\begin{array}{l}\text { I listen Amharic and Afan Oromo news programs transmitted } \\
\text { from Jimma Fana FM } 98.1 \text { because the contents of the news are } \\
\text { informative. }\end{array}$ & 72 & 39.3 & 76 & 41.5 & 23 & 12.5 & 9 & 4.9 & 7 & 3.8 \\
\hline 6 & $\begin{array}{l}\text { I listen Amharic and Afan Oromo news programs transmitted from } \\
\text { Jimma Fana FM } 98.1 \text { because the news address my personal } \\
\text { problems. }\end{array}$ & 81 & 44.2 & 59 & 32.2 & 26 & 14.2 & 8 & 4.3 & 9 & 4.9 \\
\hline 7 & $\begin{array}{l}\text { I listen Ahmaric and Afan Oromo news programs transmitted from } \\
\text { Jimma Fana FM } 98.1 \text { because the news help me to know the } \\
\text { community problems. }\end{array}$ & 70 & 38.2 & 66 & 36.05 & 29 & 15.8 & 11 & 6.01 & 1 & 0.54 \\
\hline 8 & $\begin{array}{l}\text { I listen Ahmaric and Afan Oromo news programs transmitted } \\
\text { from Jimma Fana FM } 98.1 \text { because the news influence me to be } \\
\text { concerned on different issues. }\end{array}$ & 66 & 36.06 & 72 & 39.3 & 20 & 10.9 & 10 & 5.46 & 14 & 7.6 \\
\hline 9 & $\begin{array}{l}\text { I listen Ahmaric and Afan Oromo news programs transmitted from } \\
\text { Jimma Fana FM } 98.1 \text { because they focus on my surrounding issue. }\end{array}$ & 73 & 39.8 & 81 & 44.2 & 13 & 7.1 & 7 & 3.8 & 9 & 4.9 \\
\hline 10 & $\begin{array}{l}\text { I listen Ahmaric and Afan Oromo news programs transmitted from } \\
\text { Jimma Fana FM } 98.1 \text { because they encourage me for change. }\end{array}$ & 72 & 39.3 & 70 & 38.2 & 24 & 13.1 & 8 & 4.3 & 9 & 4.9 \\
\hline
\end{tabular}

Table 1: Audience' Perceptions of Amharic and Afan Oromo News Programs Broadcasted from Jimma Fana FM 98.1 Radio Station.

As indicated in Table 1 above, 97 (53\%) and 68 (34\%) respondents replied that they strongly agreed and agreed respectively to item 1 provided to them. Item 2 asked the respondents if Amharic and Afan Oromo news programs provided credible information to them. In replying to this item, $106(57.9 \%)$ and $45(24.5 \%)$ of the respondents strongly agreed and agreed respectively that the news programs provided them credible information. Furthermore, 93(50.8\%) of the respondents strongly agreed and $56(30.6 \%)$ of them agreed that the transmission times of the news programs were suitable to them. As to the attractiveness of the news programs to audiences, 77 (42.07\%) and $65(35.5 \%)$ of the respondents strongly agreed and agreed respectively that the news programs were attractive for them. With regard to the informativeness of the contents of the news programs, $72(39.3 \%)$ and $76(41.5 \%)$ of the respondents strongly agreed and agreed respectively that the contents of the news programs were informative to them.

Item 6 further asked the respondents whether the news programs transmitted from the radio station addressed their own problems or not. In replying to this item, $81(44.2 \%)$ and $59(32,2 \%)$ of the respondents strongly agreed and agreed respectively that the news programs addressed their own problems. In item 7 , the respondents were further asked if the news programs helped them know the community problems at large. In responding to this item, 70 (38.2\%) and $66(36 \%)$ of the respondents informants strongly agreed and agreed respectively that they listened the news programs because the news programs helped them to know the problems of the community. Item 8 also asked the respondents whether the news programs influenced them to be concerned on different issues. In responding to this item, $66(36.06 \%)$ and $72(39.3 \%)$ of the respondents strongly agreed and agreed respectively that they listened the news programs because the news programs informed them to be concerned on different issues. Item 9 asked the respondents if the news programs enabled them to know what happened in their surrounding area as well. $73(39.8 \%)$ and 81 (44.2\%) of the respondents strongly agreed and agreed that the news programs enabled them to know what happened in their surrounding area. Moreover, in responding to item 10, 72 (39.3\%) and $70(38.2 \%)$ of the respondents strongly agreed and agreed respectively that the news programs motivated them for a new change.

From the above data analysis, thus, one can reasonably conclude that audiences of Amharic and Afan Oromo news programs have very good perceptions towards the news programs transmitted from Jimma Fana FM 98.1 radio station. The data gathered through focus group discussions further substantiate this conclusion. The great majority of the discussants of focus group discussions asserted that they had very good perceptions towards Amharic and Afan Oromo news programs broadcasted from the radio station. Nevertheless, some of the discussants of focus group discussions said that the news programs transmit old news lately after they had heard the news from other news sources such as EBC (Ethiopian Broadcasting Corporation) and BBC (British Broadcasting Corporation) two or three days before. As a solution to this, the discussants suggested that Amharic and Afan Oromo news programs broadcasted from Jimma Fana FM 98.1 radio station should deliver current and fresh news to their audiences on time as much as possible. These discussants of focus group discussions also said that Amharic and Afan Oromo news readers sometimes read news too fastly. Because of this, the discussants said that they miss some important information. As a solution to this, the focus group discussants suggested that the news readers should read news in a medium speed, and important information need to be retransmitted.

A discussant of focus group discussion further said that audiences sometimes do not listen Amharic and Afan Oromo news programs because of repeated electric power breakdown in Jimma town. This discussant commented that this should be improved through electric power capacity building. Furthermore, another discussant of focus group discussion said that some information obtained from government offices and transmitted through the news programs are 
not trustworthy news at all because these information are distorted and false information reported by government officers only for political consumptions. This discussant suggested that such kinds of information need to be cross-checked on the ground using the public before they are transmitted as news on Amharic and Afan Oromo news programs.

Table 2 above shows that $83(45.3 \%)$ and $68(37.1 \%)$ of the respondents strongly agreed and agreed respectively that Hello Fana program encouraged them to participate on the issues raised by the program. Moreover, $102(55.7 \%)$ and $45(24.5 \%)$ of the respondents strongly agreed and agreed respectively that the program transmitted interesting topics to them. The respondents were also asked in item 3 if concerned bodies were invited on Hello Fana program to answer the questions raised by audiences. In responding to this item, 93 $(50.8 \%)$ and $53(28.9 \%)$ of the respondents strongly agreed and agreed respectively that concerned bodies were invited on the program so as to give answers to the questions raised by audiences. Furthermore, as can be seen from Table 2 above, 79 (43.1\%) of the respondents strongly agreed and $65(35.5 \%)$ of them agreed that Hello Fana program provided sufficient information on issues when they were discussed on the program.

Moreover, as can be observed in Table 2 above, 76 (41.5\%) of the respondents strongly agreed and $72(39.3 \%)$ of them agreed that the contents of Hello Fana program were informative to audiences. In addition to this, $76(41.5 \%)$ of the respondents strongly agreed and $65(35.5 \%)$ of them agreed that the transmission time of Hello Fana program was suitable for them. In responding to item 8,66 (36.0\%) of the respondents strongly agreed and $67(36.6 \%)$ of them agreed that Hello Fana program brought change in their attitudes and perceptions.

Therefore, from the above data analysis, it is possible to conclude that Hello Fana program was positively perceived by the great majority of audiences of the program. The qualitative data gained from focus group discussions also support this conclusion. During the focus group discussions made with discussants, many discussants said that they have very good perceptions towards Hello Fana program. A discussant in a focus group discussion, however, said that some sponsors of Hello Fana program cannot be considered as indicator of good performance for the program, for it appears that the sponsors have a direct or indirect political affiliation with the ruling party in the country. This discussant said that these sponsors sponsor Hello Fana program for two reasons: firstly, they know that sponsoring the program directly promotes their business images in the public. Secondly, they think that Jimma Fana FM 98.1 radio station is a 'pro-ruling-party' radio station; so, sponsoring Hello Fana program can have other unseen benefits which make their business successful. Another discussant in a focus group discussion said that Hello Fana program is a very good program, but it does not have a power to force the concerned government officials to bring changes as to good governance. Some discussants in focus group discussions said that Hello Fana program has some problems related to its transmission time, the language use in the program (dialects and jargons which are not tailored to audiences are used by the presenters) and the style of presenting the program. These discussants suggested that the program should have presented contents using drama and other entertainments.

As can be observed in Table 3 above, item 1 asked respondents if Yebeteseb Maed program motivates them to participate on the issues raised by the program. In replying to this, 44 (24\%) of the respondents strongly agreed and $58(31.6 \%)$ of them agreed that they listened Yebeteseb Maed program because the program motivates them to participate on the issues raised by the program. Item 2 also asked the respondents if Yebeteseb Maed program gives to them experiences. In answering to this item, $51(27.8 \%)$ of the respondents strongly agreed and 49 (26.7\%) of them agreed that they listened Yebeteseb Maed program, for the program gave to them experiences. As to item $3,45(24.5 \%)$ of the respondents strongly agreed and 55 (30.0\%) them agreed that they listened Yebeteseb Maed program, for the program raised interesting issues to audiences. Furthermore, 42 (22.9\%) and $49(26.7 \%)$ of the respondents strongly agreed and agreed respectively that they listened Yebeteseb Maed program because the way of the broadcasting of the program was attractive to them. In responding to item $5,35(19.15 \%)$ and $51(27.8 \%)$ of the respondents strongly agreed and agreed respectively that they listened the program, for the transmission time of the program was suitable for them. Moreover, as can be observed in Table 3 above, item 6 asked the respondents whether a proper language style was used for broadcasting Yebeteseb Maed program or not. In answering to this item, 40 (21.8\%) and 58 (31.6\%) of the respondents strongly agreed and agreed respectively that a proper language style was used for broadcasting the program. In item 7, the respondents were asked if different professionals gave them advices on the issues raised by Yebeteseb Maed program. In responding to this item, $44(24 \%)$ and $44(24 \%)$ of the respondents strongly agreed and agreed respectively that different professionals gave them advices on the issues raised by the program. In responding to item $8,39(21.3 \%)$ and $54(29.5 \%)$ of the respondents strongly agreed and agreed respectively that the transmission of the Yebeteseb Maed program had quality. Regarding item 9, 36 (19.6\%) and 56 (30.6\%) of the respondents strongly agreed and agreed respectively that Yebeteseb Maed program helped them bring behavioral change.

From the above data analysis, one can clearly observe that the

\begin{tabular}{|c|c|c|c|c|c|c|c|c|c|c|c|}
\hline \multirow[t]{2}{*}{ No } & \multirow[t]{2}{*}{ Statements } & \multicolumn{2}{|c|}{ Strongly Agree } & \multicolumn{2}{|c|}{ Agree } & \multicolumn{2}{|c|}{ Disagree } & \multicolumn{2}{|c|}{ Strongly Disagree } & \multicolumn{2}{|c|}{ Undecided } \\
\hline & & $\mathbf{F}$ & $\%$ & $\mathbf{F}$ & $\%$ & $\mathbf{F}$ & $\%$ & $\mathbf{F}$ & $\%$ & $\mathbf{F}$ & $\%$ \\
\hline 1 & $\begin{array}{l}\text { Hello Fana program encourages me to participate on the issues } \\
\text { raised by the program. }\end{array}$ & 83 & 45.3 & 68 & 37.1 & 15 & 8.1 & 6 & 3.2 & 11 & 6.01 \\
\hline 2 & Hello Fana program transmits interesting topics to me. & 102 & 55.7 & 45 & 24.5 & 16 & 8.7 & 14 & 7.6 & 6 & 3.2 \\
\hline 3 & $\begin{array}{l}\text { Concerned bodies are invited on Hello Fana program to answer the } \\
\text { questions raised by audiences. }\end{array}$ & 93 & 50.8 & 53 & 28.9 & 22 & 12.02 & 10 & 5.4 & 5 & 2.7 \\
\hline 4 & $\begin{array}{l}\text { Hello Fana program provides sufficient information on issues when } \\
\text { they are discussed on the program. }\end{array}$ & 79 & 43.1 & 65 & 35.5 & 20 & 10.9 & 10 & 5.4 & 9 & 4.9 \\
\hline 5 & $\begin{array}{l}\text { Hello Fana program engages participants to freely express their idea } \\
\text { on different issues. }\end{array}$ & 75 & 40.9 & 67 & 36.6 & 26 & 14.2 & 8 & 4.3 & 1 & 0.5 \\
\hline 6 & The contents of the Hello Fana program are informative. & 76 & 41.5 & 72 & 39.3 & 18 & 9.8 & 11 & 6.01 & 6 & 3.2 \\
\hline 7 & The transmission time of Hello Fana program is suitable for me. & 76 & 41.5 & 65 & 35.5 & 21 & 11.4 & 10 & 5.4 & 11 & 6 \\
\hline 8 & Hello Fana program brought change in my attitudes and perceptions & 66 & 36 & 67 & 36.6 & 20 & 10.9 & 9 & 4.9 & 13 & 7.1 \\
\hline
\end{tabular}

Table 2: Audiences' Perceptions of the 'Hello Fana' Radio Program Broadcasted from Jimma Fana FM 98.1 Radio Station. 


\begin{tabular}{|l|l|}
\hline No & Statements \\
\hline 1 & $\begin{array}{l}\text { I listen Yebeteseb Maed program because the program motivates me } \\
\text { to participate on the issues raised by the program. }\end{array}$ \\
\hline 2 & $\begin{array}{l}\text { I listen Yebeteseb Maed program because the program gives to me } \\
\text { experience }\end{array}$ \\
\hline 3 & $\begin{array}{l}\text { I listen Yebeteseb Maed program because the program raises } \\
\text { interesting issues to audiences. }\end{array}$ \\
\hline 4 & $\begin{array}{l}\text { I listen Yebeteseb Maed program because the way of the } \\
\text { broadcasting of the program is attractive. }\end{array}$ \\
\hline 5 & $\begin{array}{l}\text { I listen Yebeteseb Maed program because the transmission time of } \\
\text { the program is suitable for me. }\end{array}$ \\
\hline 6 & $\begin{array}{l}\text { I listen Yebeteseb Maed program because a proper language style } \\
\text { is used for broadcasting the program. }\end{array}$ \\
\hline 7 & $\begin{array}{l}\text { I listen Yebeteseb Maed program because different professionals } \\
\text { give me advices on the issues raised by the program. }\end{array}$ \\
\hline 8 & $\begin{array}{l}\text { I listen Yebeteseb Maed program because the transmission of the } \\
\text { program has quality }\end{array}$ \\
\hline 9 & $\begin{array}{l}\text { I listen Yebeteseb Maed program because the program helps me } \\
\text { bring behavioral change. }\end{array}$ \\
\hline
\end{tabular}

\begin{tabular}{|c|c|c|c|c|c|c|c|c|c|}
\hline \multicolumn{2}{|c|}{ Strongly Agree } & \multicolumn{2}{|c|}{ Agree } & \multicolumn{2}{|c|}{ Disagree } & \multicolumn{2}{|c|}{ Strongly Disagree } & \multicolumn{2}{|c|}{ Undecided } \\
\hline $\mathbf{F}$ & $\%$ & $\mathbf{F}$ & $\%$ & $\mathbf{F}$ & $\%$ & $\mathbf{F}$ & $\%$ & $\mathbf{F}$ & $\%$ \\
\hline 54 & 24 & 58 & 31.6 & 9 & 4.9 & 4 & 2.1 & 5 & 2.7 \\
\hline 45 & 27.8 & 49 & 26.7 & 8 & 4.3 & 4 & 2.1 & 8 & 4.3 \\
\hline 42 & 22.9 & 49 & 26.7 & 14 & 7.6 & 6 & 3.2 & 9 & 4.9 \\
\hline 35 & 19.15 & 51 & 27.8 & 22 & 12 & 4 & 2.1 & 8 & 4.3 \\
\hline 40 & 21.8 & 58 & 31.6 & 12 & 6.5 & - & - & 10 & 5.4 \\
\hline 34 & 24 & 44 & 24 & 12 & 6.5 & 3 & 1.6 & 6 & 3.2 \\
\hline 36 & 21.3 & 54 & 29.5 & 15 & 8.1 & 5 & 2.7 & 7 & 3.8 \\
\hline
\end{tabular}

Table 3: Audiences' Perceptions of the 'Yebeteseb Maed' Radio Program Broadcasted from Jimma Fana FM 98.1 Radio Station.

\begin{tabular}{|l|l|}
\hline No & Statements \\
\hline 1 & The Tibeb Fana program is participatory \\
\hline 2 & The Tibeb Fana program entertains me. \\
\hline 3 & The content of the Tibeb Fana program is informative. \\
\hline 4 & TheTibeb Fana program influences me to develop my art ability. \\
\hline 5 & The way of Tibeb Fana program's transmission is attractive to me \\
\hline 6 & The Tibeb Fana program transmission time is suitable to me. \\
\hline 7 & $\begin{array}{l}\text { Appropriate language use style is used in broadcasting the Tibeb } \\
\text { Fana program. }\end{array}$ \\
\hline 8 & The Tibeb Fana program transmission has quality. \\
\hline
\end{tabular}

\begin{tabular}{|c|c|c|c|c|c|c|c|c|c|}
\hline \multicolumn{2}{|c|}{ Strongly Agree } & \multicolumn{2}{|c|}{ Agree } & \multicolumn{2}{c|}{ Disagree } & \multicolumn{2}{c|}{ Strongly Disagree } & \multicolumn{2}{c|}{ Undecided } \\
\hline $\mathbf{F}$ & $\%$ & $\mathbf{F}$ & $\%$ & $\mathbf{F}$ & $\%$ & $\mathbf{F}$ & $\%$ & $\mathbf{F}$ & $\%$ \\
\hline 91 & 49.7 & 73 & 39.8 & 11 & 6 & 3 & 1.6 & 6 & 3.2 \\
\hline 102 & 55.7 & 60 & 32.7 & 8 & 4.3 & 5 & 2.7 & 6 & 3.2 \\
\hline 77 & 42 & 65 & 35.5 & 11 & 6 & 9 & 4.9 & 16 & 8.7 \\
\hline 71 & 38.7 & 77 & 42 & 11 & 6 & 9 & 4.9 & 17 & 9.2 \\
\hline 77 & 42 & 79 & 43.1 & 17 & 9.2 & 5 & 2.7 & 5 & 2.7 \\
\hline 73 & 41.5 & 70 & 38.2 & 22 & 12 & 12 & 6.5 & 7 & 3.8 \\
\hline 70 & 39.8 & 81 & 44.2 & 21 & 11.4 & 7 & 3.8 & 4 & 2.1 \\
\hline
\end{tabular}

Table 4: Audiences' Perceptions of the 'Tibeb Fana' Radio Program Broadcasted from Jimma Fana FM 98.1 Radio Station.

respondents' answers positively skewed towards the options 'strongly agree' and 'agree' to all the items provided to the respondents. From this, thus, it is possible to conclude that audiences of Yebeteseb Maed program have very good perceptions towards the program. The focus group discussions results further confirm this conclusion. In focus group discussions made with discussants, the majority of the discussants said that they liked Yebeteseb Maed program very much because the program transmits very valuable information regarding marriage, love and family which are directly related to their life. Nevertheless, a discussant in a focus group discussion commented that Yebeteseb Maed program mainly educates its audiences about family love. But the program does not educate its audiences about other types of love such as love of a community and a country. Still, another participant in a focus group discussion said that some individuals who do not have special expertise, credibility and authority give unsatisfactory and sometimes shameful answers to the questions raised by audiences on the program. As a result, this discussant implied that the fallacy of 'irrelevant authority' is sometimes committed on Yebeteseb Maed program. Some participants in focus group discussions further said that the participation of women audiences is very minimum on the program it is males who give their comments and suggestions on the family, love and marriage related issues raised on Yebeteseb Maed program. This could be because of different reasons that need further investigation. Moreover, some discussants of focus group discussions complained that Yebeteseb Maed program transmission time is not convenient to them because they are busy with household responsibilities during the day time. Thus, these discussants commented that the program should be transmitted in the weekends or evening as well.
As can be seen in Table 4 above, the informants were asked if the Tibeb Fana program was participatory in item 1. In answering to this item, $91(49.7 \%)$ and $73(39.8 \%)$ of the respondents strongly agreed and agreed, respectively that the Tibeb Fana program was participatory. In responding to item 2, $102(55.7 \%)$ and $60(32.7 \%)$ of the respondents further strongly agreed and agreed respectively that the program entertained them. As to the informativeness of the content of the program, 77 (42.0\%) of the respondents strongly agreed that the content of the Tibeb Fana program was informative and 65 $(35,5 \%)$ of them agreed the content of the program was informative. Item 4 asked if the Tibeb Fana program influenced the respondents to develop their art ability. In responding to this item, 71 (38.7\%) and 77 $(42.0 \%)$ of the respondents strongly agreed and agreed respectively that the program influenced them to develop their art ability. With regard to the attractiveness of the program to audiences, as can be observed in the table above, $77(42.0 \%)$ and $79(43.1 \%)$ of the respondents strongly agreed and agreed respectively that the Tibeb Fana program was attractive to them. Item 6 asked if the Tibeb Fana program transmission time was suitable to audiences. In answering to this item, $76(41.5 \%)$ and $70(38.2 \%)$ of the respondents strongly agreed and agreed respectively that the Tibeb Fana program transmission time was suitable to audiences. Furthermore, in responding to item $7,73(39.8 \%)$ and $81(44.2 \%)$ of the respondents strongly agreed and agreed respectively that appropriate language use style was used in broadcasting the Tibeb Fana program. Moreover, in answering to item $8,70(38.2 \%)$ and $78(42.6 \%)$ of the respondents strongly agreed and agreed respectively that the Tibeb Fana program transmission had quality to audiences. 
From the above data analysis, one can clearly see that the respondents' answers positively leaned towards the options 'strongly agree' and 'agree' to all the items provided to the respondents. Therefore, from this, one can arguably conclude that audiences of the Tibeb Fana program have very good perceptions towards the program. The finding of focus group discussions further supports this conclusion. In all the focus group discussions made with discussants, many discussants (particularly the youths) said that they liked the Tibeb Fana program. It was reflected that the issues transmitted on the program are very important for young people. However, some discussants in focus group discussions mentioned that many talented youths they know do not participate on the Tibeb Fana program because of their financial problem. A participant in a focus group discussion also remarked that the program transmits about limited arts - all arts are not transmitted on the program. Hence, the Tibeb Fana program could not cultivate diversified arts found in the community as such.

As can be seen in Table 5 above, the respondents were asked if the content of the Gaddisa Jimata news program was informative in item 1 . In responding to the item, $44(24.0 \%)$ and $10(5.4 \%)$ of the respondents strongly agreed and agreed respectively that the content of the news program was informative to audiences. Pertaining to item $2,32(17.4 \%)$ and $26(14.2 \%)$ of the informants strongly agreed and agreed respectively that the Gaddisa Jimata news program presented local news to them. With regard to item 3, $38(20.7 \%)$ and $18(9.8 \%)$ of the respondents strongly agreed and agreed respectively that the way of broadcasting of the Gaddisa Jimata news program was attractive to them. As to item 4, $28(15.3 \%)$ and $25(13.6 \%)$ of the respondents strongly agreed and agreed respectively that the transmission time of the Gaddisa Jimata news program was suitable for them. Item 5 asked the respondents whether the Gaddisa Jimata news program provided them new information. In answering to this item, 30 (16.3\%) and 26 $(14.2 \%)$ of the respondents strongly agreed and agreed respectively that the news program provided them new information. Furthermore, item 6 asked the respondents if the transmission of Gaddisa Jimata news program had quality. In responding to this item, 31 (16.9\%) and 25 $(13.6 \%)$ of the respondents strongly agreed and agreed respectively that the transmission of Gaddisa Jimata news program had quality.

From the above data analysis it is evident that the respondents' responses positively inclined towards the options 'strongly agree' and 'agree' to all the items presented to the respondents. Therefore, one can conclude from this that audiences of the Gaddisa Jimata news program have very good perceptions towards the news program. The results gained from focus group discussions further support this conclusion. However, the discussants of focus group discussions said that the Gaddisa Jimata news program emphasizes on transmitting premium league sport news which are not local and national sport. In this regard, a discussant in a focus group discussion added that though there are sports in Jimma zone these days, these sports are not sufficiently reported by the news program.

\section{Conclusions and Recommendations}

\section{Conclusions}

The following conclusions are drawn based on the major findings of the study:

In general, audiences of Jimma Fana FM 98.1 radio station have very good perceptions towards the five informative programs viz. Ahmaric and Afan Oromo news programs, Hello Fana program, Yebeteseb Mead program, Tibeb Fana program and Gaddisa Jimmata news program broadcasted from the radio station. However, the five informative programs have also the following drawbacks:

A. Ahmaric and Afan Oromo news programs transmit old news lately to their audiences. Furthermore, Ahmaric and Afan Oromo news readers sometimes read news too fastly. Audiences of Ahmaric and Afan Oromo news programs sometimes do not listen the news programs because of repeated electric power breakdown in Jimma town as well. Moreover, some untrustworthy, distorted and false information obtained from government offices are transmitted through the Ahmaric and Afan Oromo news programs to audiences.

B. Some sponsors of Hello Fana program have a direct or indirect political affiliation with the ruling party in the country. Thus, these sponsors of Hello Fana program cannot be considered as indicator of good performance for the program. Furthermore, Hello Fana program lacks a power to force the concerned government officials to bring changes as to good governance. The program further has some problems related to its transmission time, the language use in the program (dialects and jargons which are not tailored to audiences are used by the presenters) and the style of presenting the program.

C. Yebeteseb Maed program mainly educates its audiences about family love, but the program does not educate its audiences about other types of loves such as love of a community and a country. Moreover, some individuals who do not have special expertise, credibility and authority give unsatisfactory and sometimes shameful answers to the questions raised by audiences on the program. As a result, the fallacy of 'irrelevant authority' is sometimes committed on Yebeteseb Maed program. In addition to this, the participation of women audiences is very minimum on the program - it is males who give their comments and suggestions on the family, love and marriage related issues raised on Yebeteseb Maed program. Moreover, Yebeteseb Maed program transmission time is not convenient to some audiences because they are busy with household responsibilities during the day time.

\begin{tabular}{|c|c|c|c|c|c|c|c|c|c|c|c|}
\hline \multirow[t]{2}{*}{ No } & \multirow[t]{2}{*}{ Statements } & \multicolumn{2}{|c|}{ Strongly Agree } & \multicolumn{2}{|c|}{ Agree } & \multicolumn{2}{|c|}{ Disagree } & \multicolumn{2}{|c|}{ Strongly Disagree } & \multicolumn{2}{|c|}{ Undecided } \\
\hline & & $\mathbf{F}$ & $\%$ & $\mathbf{F}$ & $\%$ & $\mathbf{F}$ & $\%$ & $\mathbf{F}$ & $\%$ & $\mathbf{F}$ & $\%$ \\
\hline 1 & The content of the Gaddisa Jimata news program is informative. & 44 & 24 & 10 & 5.4 & 5 & 2.7 & 4 & 2.1 & - & - \\
\hline 2 & $\begin{array}{l}\text { I listen the Gaddisa Jimata news program because it presents local } \\
\text { news. }\end{array}$ & 32 & 17.4 & 26 & 14.2 & 4 & 2.1 & - & - & 1 & 0.5 \\
\hline 3 & $\begin{array}{l}\text { I listen the Gaddisa Jimata news program because the way of } \\
\text { broadcasting of the news program is attractive }\end{array}$ & 38 & 20.7 & 18 & 9.8 & 5 & 2.7 & - & - & 2 & 1 \\
\hline 4 & $\begin{array}{l}\text { I listen the Gaddisa Jimata news program because the transmission } \\
\text { time of the news program is suitable for me. }\end{array}$ & 28 & 15.3 & 25 & 13.6 & 8 & 4.3 & 2 & 1 & - & - \\
\hline 5 & $\begin{array}{l}\text { I listen the Gaddisa Jimata news program because the news } \\
\text { program provides me new information. }\end{array}$ & 30 & 16.3 & 26 & 14.2 & 3 & 1.6 & 4 & 2.1 & - & - \\
\hline 6 & $\begin{array}{l}\text { I listen the Gaddisa Jimata news program because the transmission } \\
\text { of news program has quality. }\end{array}$ & 31 & 16.9 & 25 & 13.6 & 5 & 2.7 & 2 & 1 & - & - \\
\hline
\end{tabular}

Table 5: Audiences Perceptions of the 'Gaddisa Jimmata' News Program Broadcasted from Jimma Fana FM 98.1 Radio Station. 
D. Many talented youths do not participate on the Tibeb Fana program because of their financial problem. Moreover, the program transmits about limited arts - all arts are not transmitted on the program. Thus, the Tibeb Fana program could not cultivate diversified arts found in the community as such.

E. Gaddisa Jimata news program emphasizes on transmitting premium league sport news, which are not local and national sport. For instance, though there are sports in Jimma zone these days, these sports are not sufficiently reported by the news program to audiences.

\section{Recommendations}

Based on the major findings and conclusions of the study, the following recommendations have been suggested:

Amharic and Afan Oromo news programs broadcasted from Jimma Fana FM 98.1 radio station should deliver current and fresh news to their audiences on time as much as possible.

Ahmaric and Afan Oromo news readers should read news in a medium speed so that the news listeners properly comprehend the news. It would be advisable if important top news are retransmitted to audiences as well.

The management of Jimma Fana FM 98.1 radio station should discuss the ways of improving electric power breakdown with the concerned bodies so that audiences of the radio station get transmission without electric power interruption. Alternatively, the radio station can buy a generator so as to transmit programs to its audiences without electric power interruption.

Some untrustworthy, distorted and false information obtained from government offices are transmitted through the Ahmaric and Afan Oromo news programs to audiences. Thus, news information obtained from government offices need to be cross-checked on the ground using the public before they are transmitted as news to audiences through Amharic and Afan Oromo news programs.

The transmission time of Hello Fana program and Yebeteseb Maed program should be convenient to audiences so that the audiences of the programs properly attain these informative programs. Thus, the management of Jimma Fana FM 98.1 radio station needs to adjust the transmission time of these programs to audiences. For example, the two programs can be transmitted to audiences in the weekends or evening when audiences are relatively free.

It would be advisable if presenters of Hello Fana program tailor the dialects and jargons they use to audiences so that the audiences of the program attain the program without communication-breakdown. Moreover, it would be advisable if the presentation styles of the program are reconsidered. For instance, drama and other entertainments can be used to transmit contents of the program.

Many talented youths do not participate on the Tibeb Fana program because of their financial problem. Thus, the management of Jimma Fana FM 98.1 radio station should give at least some money as incentives to talented youths so as to motivate these youths to participate on the program. Moreover, the Tibeb Fana program should cultivate diversified arts found in the community instead of transmitting about only limited types of arts.

\section{References}

1. Mughees-uddin (1991) The relationship between a nation's foreign policy and its press: The case of Pakistan and the New York Times and the Time of London in 1980. Unpublished MA thesis. The University of IOWA.
2. Croteau D, Hoynes W, Milan S (2009) Media and society: Industries, images and audiences (4th ed.), Los Angeles: Sage Publication.

3. McCombs, Maxwell E (2005) A look at agenda-setting: Past, present and future. Journal of Journalism Studies 6: 543-557.

4. Severin J (2001) Communication theories: origins, methods and uses in mass media (5th edn.). London: Longman.

5. Matthes $\mathrm{J}$ (2011) The Affective underpinnings of hostile media perceptions Exploring the distinct effects of affective and cognitive involvement. Joural of Communication Research 40: 360-387.

6. Amin H (2010) Freedom as a value in Arab media: Perceptions and attitudes among Journalists. Journal of Political Communication 19: 125-135.

7. D'Angelo P, Lombard M (2014) The power of the press: The effects of press frames in political campaign news on media perceptions. Atlantic Journal of Communication 16: 1-32

8. Milkesa C (2010) FM radios for social development: A case study of Zami FM 90.7 and Sheger FM. 102.1. Unpublished MA thesis. Addis Ababa University.

9. Biset A (2014) Media preferences and perceptions: The case of Bahir Dar University instructors. Journal of Media and Communication Studies 6: 179185.

10. Berger A (2014) Media analysis techniques (5th edn.), Los Angeles: Sage Publications.

11. Maxwell MC (2002) Agenda setting role of mass media in shaping public opinion. University of Texas.

12. Braisby N, Gellatly A (2005) Cognitive psychology. Oxford: Oxford University Press.

13. Chan A (2007) Guiding public opinion through social agenda setting: China's media policies. Journal of Contemporary China 16: 547-559.

14. Styhre A (2008) Perception and organization: Art, music, media. New York: Palgrave.

15. Littlejohn S, Foss K (2009) Encyclopedia of communication theory. California: Sage Publications

16. Wood J (2006) Communication mosaics: An introduction to the field of communication (6th edn.), Boston: Wadsworth.

17. Vaus D (2001) Research design in social research. London: Sage Publications.

18. Bloor M, Wood F (2006) Keywords in qualitative methods: A vocabulary of research concepts. London: Sage Publications. 